\title{
Partículas em Rikbaktsa
}

\section{Particles in Rikbaktsa}

\author{
Léia de Jesus Silva \\ Universidade Federal de Goiás. Goiás, Goiânia, Brasil
}

\begin{abstract}
Resumo: Em Rikbaktsa (Macro-Jê), as partículas constituem uma classe léxica, ao lado de advérbios e posposições. Em geral, as partículas são descritas como elementos invariáveis; nesta língua, entretanto, há dois conjuntos de partículas, um marcando focalização e o outro, modalização de empatia, que apresentam uma complexidade morfológica envolvendo o gênero e o número dos participantes. Há, ainda, evidências fonológicas e morfossintáticas que contribuem para a distinção entre partículas e clíticos. Dentre os muitos significados expressos pelas partículas da língua, identificamos focalização, modalidade epistêmica e evidencialidade. Em se tratando da categoria de evidencialidade, o verbo auxiliar da língua está passando por um processo de gramaticalização para indicar reportativo.
\end{abstract}

Palavras-chave: Língua Rikbaktsa. Partículas. Topicalização. Evidencialidade. Gramaticalização.

Abstract: In Rikbaktsa (Macro-Jê), particles comprise a lexical class alongside adverbs and postpositions. Usually particles are described as invariant elements in this language; however, there are two sets of particles, one marking focalization and another denoting modality of empathy, which present a morphological complexity involving the genre and number of the focalized element in the former element and the genre and number of the speaker/istener in the latter. Among the many meanings expressed by these language particles, I identified focalization, epistemic modality, and evidentiality. In terms of the evidentiality category, the auxiliary verb is undergoing a process of grammaticalization to indicate the reportative.

Keywords: Rikbaktsa language. Particles. Topicalization. Evidentiality. Grammaticalization.

SILVA, Léia de Jesus. Partículas em Rikbaktsa. Boletim do Museu Paraense Emílio Goeldi. Ciências Humanas, Belém, v. 14, n. 3, p. 873896, set.-dez. 2019. DOI: http://dx.doi.org/10.1590/1981.81222019000300010.

Autora para correspondência: Léia de Jesus Silva. Universidade Federal de Goiás. Avenida Esperança, s./n. Campus Samambaia. Goiás, GO, Brasil. CEP 74605-220 (leiajs@gmail.com).

Recebido em 15/05/2019

Aprovado em 21/10/2019

(c) (i)

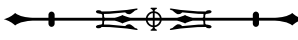




\section{INTRODUÇÃO}

A língua Rikbaktsa1 possui as classes léxicas de nome, verbo, advérbio, posposição e partículas (Silva, 2011). Todas estas partes do discurso são caracterizadas com base em critérios formais identificados na língua. O conjunto de formas livres que agrupamos em uma classe com o rótulo de 'partículas' tem escopo sobre a proposição ou sobre constituintes específicos, apresenta função pragmática e, ao contrário das demais classes, que têm a propriedade de predicar, as partículas não predicam, porém podem instituir uma oração independente. Neste artigo, descreveremos a distribuição e o uso desse conjunto de formas em Rikbaktsa.

Do ponto de vista teórico, diferentemente de categorias como advérbio e posposição, por exemplo, no que se refere às partículas, não é unanimidade as considerar uma classe. Alguns autores defendem que não é necessário postular uma categoria de partículas para elementos que podem facilmente ser classificados em categorias já existentes nas línguas (Zwicky, 1985); outros sequer listam as partículas dentre as partes do discurso (Schachter, 1985; Lemaréchal, 1989; Givón, 2001); e há quem as considere como uma classe léxica (Payne, 2006). Apresentaremos abaixo propriedades formais que julgamos pertinentes para propor que, em Rikbaktsa, as partículas constituem uma classe léxica.

Este artigo está organizado em duas partes: na primeira, apresentamos as características gerais das partículas, e na segunda, o inventário das mesmas.

Os dados usados para a elaboração deste trabalho foram coletados pela autora junto a falantes nativos em diversas idas a campo. Todos os exemplos são retirados de textos - narrativas míticas, procedurais ou discurso cotidiano.

\section{CARACTERÍSTICAS GERAIS DAS PARTÍCULAS}

Passamos a apresentar as características das partículas do Rikbaktsa, contrastando-as com características de outras partes do discurso. Serão também contrastadas as propriedadades de partículas e clíticos na língua.

Para Silva (2011), as partículas se diferem das outras classes léxicas da língua sintática e morfologicamente. Sintaticamente, elas não instituem um predicado, diferentemente do que ocorre com as demais classes. Do ponto de vista morfológico, verbo, advérbio e posposição podem se combinar com clíticos nominalizadores para formar nomes, enquanto as partículas não têm essa propriedade. E no que se refere aos nomes, estes se flexionam, obrigatória ou opcionalmente, para a pessoa do possuidor, e as partículas não. $\bigcirc$ Quadro 1 abaixo resume a comparação entre partículas e as demais classes léxicas da língua²:

Quadro 1. Comparativo entre partículas e demais classes léxicas.

\begin{tabular}{|c|c|c|c|c|c|}
\hline & Nomes & Verbos & Advérbios & Posposições & Partículas \\
\hline Instituir predicado & + & + & + & + & - \\
\hline Admitir clítico nominalizador & - & + & + & + & - \\
\hline Flexão de pessoa do possuidor & + & - & - & - & - \\
\hline
\end{tabular}

\footnotetext{
A língua Rikbaktsa, classificada como pertencente ao tronco linguístico Macro-Jê, é falada pelos Rikbaktsa, povo que vive no noroeste do estado de Mato Grosso.

2 A categoria de tempo difere os verbos das demais classes, incluindo advérbio, uma vez que só os verbos admitem marcação de tempo.
}

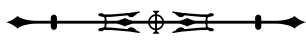


Como se vê, é tentador definir a classe de partículas pelo que seus membros não têm ou não são. Para ir além desta caracterização negativa que, em geral, acompanha a definição desta classe - e sobre a qual fala criticamente Zwicky (1985), seguem outras propriedades fonológicas, morfossintáticas e semânticas da classe de partículas nesta língua (Silva, 2011, p. 216):

a. têm acento próprio;

b. podem ser morfologicamente complexas;

c. aparecem pospostas ao constituinte sobre o qual têm escopo;

d. podem instituir uma oração independente;

e. em relação à posição na sentença, podem ser intrassentenciais e extrassentenciais;

f. do ponto de vista semântico, expressam noções pragmáticas, como focalização, modalidade e evidencialidade.

Das propriedades listadas acima, nos deteremos nas fonológica (a) e morfológica (b). No que diz respeito ao item a, ele aponta para uma característica das partículas que as diferencia dos clíticos: aquelas são acentuadas e estes, não. Há, ainda, outro aspecto da gramática do Rikbaktsa onde esta distinção fica evidente, quando comparamos as partículas de foco e empatia com os clíticos nominalizadores ${ }^{3}$. Estes últimos constituem um conjunto de elementos que têm a mesma origem e praticamente a mesma forma das partículas de foco e modalização de empatia - discutidas adiante -, o que poderia nos levar a pensar que se trata das mesmas formas. Veremos, entretanto, que não são, e que, para além do acento, a distribuição e a função de clíticos e partículas são bem claras e apontam para elementos de naturezas distintas.

Os clíticos participam de processos morfossintáticos que não admitem partículas, como demonstrado em (1); têm uma distribuição mais fixa na sentença; e parecem ser mais relevantes para a sintaxe do que as partículas. Naturalmente que este último ponto é determinado pela semântica de cada clítico, mas, ao que parece, em geral, as partículas teriam funções que lhes permitiriam ser sintática e morfologicamente mais opcionais em comparação aos clíticos.

Em (1), o clítico ta nominaliza o sintagma posposicional ske=bete 'sobre o caminho', e a nominalização resultante, $s k e=$ bete $=$ ta 'o que está sobre o caminho', vira objeto da posposição clítica bete 'sobre'.

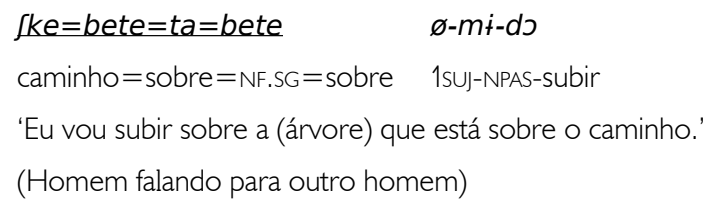

As partículas de foco e empatia podem co-ocorrer com a forma nominalizada:

$\begin{array}{lllll}\text { uta } & \text { kta } & \text { Ske=bete }=\underline{\text { ta }}=\text { bete } & \varnothing-m \dot{-}-d \supset & k t a \\ \text { eulM } & \text { FOC.NF.SG } & \text { caminho=sobre }=\text { NF.SG }=\text { sobre } & \text { 1sUJ-NPAS-subir } & \text { EMP.NF/NF }\end{array}$

'Eu é que vou subir sobre a (árvore) que está sobre o caminho!'

O clítico ta está fonologicamente preso ao lexema, enquanto ambas as partículas são fonológica, morfológica e sintaticamente independentes.

\footnotetext{
3 Para mais informações sobre os clíticos nominalizadores, ver Silva (2011).
}

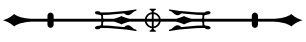


O item b, por sua vez, pode trazer certa complicação para a definição tipológica de partículas, frequentemente definidas como formas invariáveis (Payne, 2006; Crystal, 2008). O Rikbaktsa tem dois conjuntos de partículas focalizadoras e modalizadoras de empatia - que têm a mesma origem e cujas formas são morfologicamente complexas. Como veremos mais adiante, estas partículas variam em função do gênero e do número do referente do constituinte focalizado, e em função do gênero e do número do falante e do ouvinte, no caso da modalização de empatia.

A referência ao gênero e ao número dos participantes sintáticos ou discursivos toca verbos, nomes - e as subclasses de pronomes independentes e pró-formas indefinidas - e demonstrativos. Operações morfossintáticas como a nominalização e a formação de predicados atributivos também são sensíveis ao gênero. Dessa maneira, o fato de as partículas serem atingidas por esse traço tão geral da língua só corrobora a coerência interna do sistema ${ }^{4}$.

Feitas estas considerações sobre as características das partículas, passamos a descrever forma, significado e distribuição das mesmas.

\section{INVENTÁRIO DAS PARTÍCULAS}

Segue o inventário das partículas do Rikbaktsa:

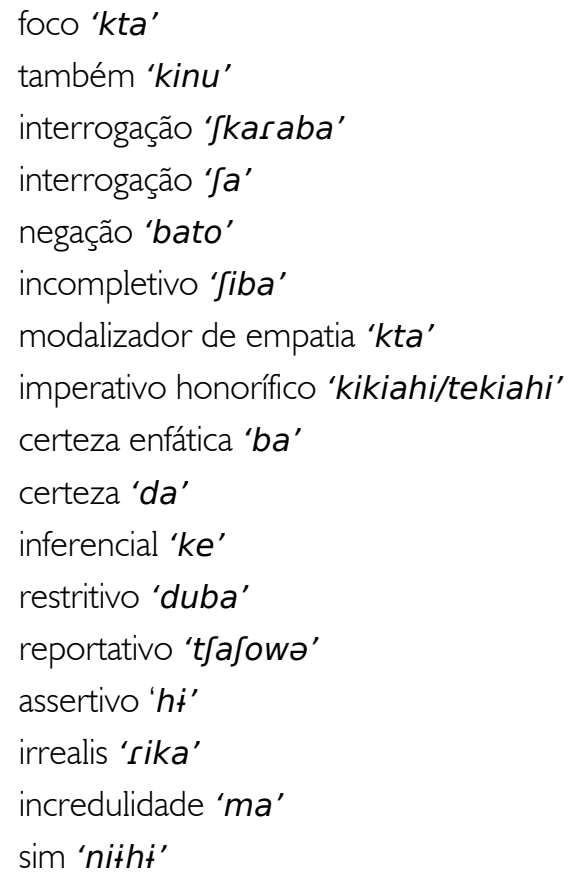

É possível combinar uma sequência de até três partículas - ver exemplo (7). Estando presente a partícula de foco, ela terá primazia pela segunda posição na sentença, como vemos em (7), (8), (22) e (43). Passamos a descrever e exemplificar as partículas do Rikbaktsa, considerando a ordem do inventário dado acima.

\footnotetext{
4 Partículas variando em função do gênero dos participantes também são identificadas, por exemplo, em línguas africanas. Para mais informações, ver Caron (2000).
}

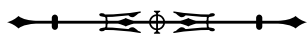


- Foco 'kta, ktfa e katja's: as partículas deste conjunto (Quadro 2) aparecem na segunda posição na sentença, imediatamente após o constituinte focalizado - em geral um sintagma nominal na função de sujeito -, e variam em função do gênero e do número do referente deste.

Quadro 2. Partículas focalizadoras.

\begin{tabular}{|c|c|c|}
\hline & Singular & \multicolumn{2}{c|}{ Plural } \\
\hline Feminino & \multicolumn{2}{|c|}{ katfa } \\
Não feminino & kta & $k$ tja \\
\hline
\end{tabular}

Se o referente é feminino, a distinção de número é neutralizada e o foco é marcado pela partícula katfa; sendo o referente não feminino, singular e plural, o foco é marcado por kta e ktfa, respectivamente.

Estas partículas têm origem nas marcas de gênero e número da língua (tatfa 'F.SG', ta 'NF.SG' e tJa 'NF.PL'); e como marcadores de foco, são formadas por estas marcadas antecedidas da forma $k$ (Silva, 2011) ${ }^{6}$.

É quase sempre o constituinte na função de sujeito que é focalizado. Nos trechos abaixo, fica clara a função focalizadora destas partículas, pois elas são usadas sempre que um novo participante é introduzido na narrativa, além de estarem em contexto de foco contrastivo.

Genro e sogra estão no mato, ela ouve o barulho dos bichos e começa a perguntar a ele de que bicho se trata:

$\begin{array}{lllllll}\text { (3) } m i \tilde{j} k t J a, & \text { ta } & \underline{k t a} & \text { Ja } & h a=w a & \varnothing-m \dot{i}-\varnothing, & m i \tilde{j} k t \int a \\ \text { genro } & \text { este } & \text { FOC.NF.SG } & \text { INTER } & \text { INTER=COMo } & \text { 3sUJ-NPAS-AUX } & \text { genro }\end{array}$

'Genro, e este, como ele faz, genro?

$\begin{array}{lllll}\text { ta } & \text { kta } & \text { aha-raro } & \text { tihi } & k t \int a \\ \text { este } & \text { FOC.NF.SG } & \text { 2PL.POSS-mingau } & ? & \text { EMP.NF/F }\end{array}$

É com este que vocês fazem o mingal de vocês! (litt.: este é que é o mingau de vocês)

$[\ldots]$

$\begin{array}{llll}\underline{\text { ta }} & \underline{\text { kta }} & \text { Ja } & h a=w a \\ \text { este } & \text { FOC.NF.SG } & \text { INTER } & \text { INTER }=\text { COMO }\end{array}$

E este, como ele faz?

ta kta $\quad i-t \int a p o-k o=t a \quad k t \int a$

este FOC.NF.SG 3sG.POSS-dente-CONT=NF.SG EMP.NF/F

Este é um que tem dentes.'

5 Esta análise difere da presente em Silva (2011), que chama estas partículas de marcadores de tópico.

6 No caso da forma kat $a$, única dissilábica dentre as partículas focalizadoras, ela é resultado de um processo morfofonológico onde a

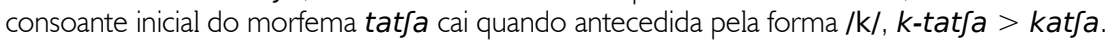

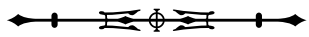


Note-se, nestes dados, a presença da partícula final $k t \int a$, que, apesar da semelhança com as partículas focalizadoras, pertence ao conjunto de partículas marcadoras de empatia, vistas mais adiante.

No extenso corpus de que disponho, são raros os casos de focalização de objeto e circunstancial. Em (4), atikitta funciona como objeto, sendo que, além da partícula focalizadora, a organização discursiva da sentença reforça a focalização por meio do deslocamento deste constituinte à esquerda, aparecendo em uma posição ex situ, resultando, assim, em uma sentença cuja ordem é OSV (Objeto Sujeito Verbo).

(4) a-tiki-tja ktja ka-ro ni-ø- $\int i=b a=h i k$

2sG.POSS-irmão-NF.PL FOC.NF.PL 1SG.POSS-Pai 3sUJ-PAS-3PL.OBJ-matarlPL=PONT

'Foram seus irmãos que meu pai matou todos.'

Nos exemplos seguintes, o foco está sobre os circunstanciais, tapara (5) e na=ere (6). Em (5), o referente com o qual a partícula de foco concorda é o sujeito do verbo, a onça - personagem masculino que está expresso pelo índice de pessoa tfi- '2suj'; em (6), o sujeito é um personagem mítico (Põnopõno), também masculino, expresso pelo índice pessoal ø- '3suj':

$\begin{array}{llll}\text { tapara } & \text { kta } & t i=[-i k-t / i t a & t \int i-m i-\varnothing \\ \text { primeiramente } & \text { FOC.NF.SG } & \text { IMP.SG=DIR-1SG.OBJ-moquear } & \text { 2sUJ-NPAS-AUX }\end{array}$

'Primeiramente mesmo, me moquei!'

(Homem dando instruções à onça, a fim de enganá-la)

(6) na=ere kta Jkaraba

aqui $=$ INES FOC.NF.SG INTER

$\begin{array}{lll}\varnothing \text {-mí-romo } & \varnothing-m \dot{t}-\text {-romo } & \varnothing-m \dot{t} \text {-romo } \\ \text { 3sUJ-NPAS-chegar } & 3 \text { SUJ-NPAS-chegar } & 3 \text { SUJ-NPAS-chegar }\end{array}$

'De onde é que ele (Põnopõno) chega sempre?'

As partículas de foco podem coocorrer com outras partículas, como ke 'inferência' e ba 'certeza enfática', por exemplo. Como já dito, em todos os casos de coocorrência com outras partículas, é a marca de foco que virá na segunda posição, imediatamente à direita do constituinte sobre o qual tem escopo:

(7) ata kta ke $\underline{b a}$ ata $=$ to $n i-\varnothing-a p i-k i k=$ to

ele FOC.NF.SG INFER C.ENF ele $=$ ENF 3sUJ-PAS-esperar-CONT $=E N F$

'Parece que era ele mesmo, ele mesmo que estava esperando.'

- Também 'kinu': muito produtiva na língua, esta partícula funciona como uma espécie de conjunção aditiva, e tem por escopo o sintagma à esquerda dela. Na continuação da narrativa mostrada em (3), quando a sogra ouve outro bicho e pergunta ao genro de que bicho se trata, ele responde:

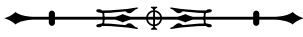




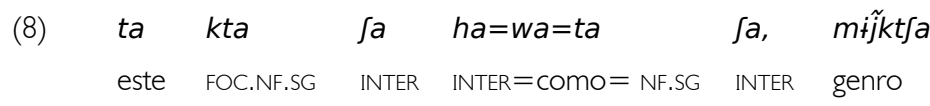

'E este, ele é um que faz como, genro?

ta kinu niwa tihi aha-raro tihi

este também como ? 2PL.Poss-mingau ?

Este também faz igual, é o mingau de vocês.'

(9) uta kinu da $\quad$ ø-pi-ø-əkpə

eulM também CERT 1SUJ-NPAS-3SG.OBJ-experimentar

'Certamente eu também vou experimentar.'

(Resposta do veado ao sapo, após este lhe dizer como havia feito para ter as pernas grossas)

Apesar de quase sempre ter por escopo um constituinte na função de sujeito, kinu pode ter como escopo constituintes em função de objeto (10) e circunstancial (11):

\begin{tabular}{|c|c|c|c|c|}
\hline mokJ-t〕a-ti & kinu & $n a=w a$ & tihi & $t \int i-m-a=h a$ \\
\hline mandioca-NF.PL-ACUS & também & isto $=$ como & $?$ & $2 S U J-N P A S-A U X=P L$ \\
\hline
\end{tabular}

'(Com) mandioca também vocês farão asssim.'

$(11)$

$\begin{array}{llllll}\text { jobo } & \text { kinu } & \text { niwa } & \text { tihi } & \text { t } \text { ji-mi-difaha-wə-ẽ-na } & k t \int a \\ \text { céu } & \text { também como } & ? & \text { 3sG-1PL.OBJ-comer-N.PAC-EST.AFIR-NF.DIF } & \text { EMP.NF/NF.PL }\end{array}$

'No céu também é assim mesmo, tem muita comida.'

(Mãe dizendo para a filha, que estava se alimentando)

Nas narrativas, quando há uma sequência de eventos, é muito comum kinu introduzir um discurso direto. Aqui, como nos exemplos acima, kinu tem por escopo o sintagma à sua esquerda, que nestes casos tem como referente o autor do discurso:

(12) witik kinu t ti-k-[-ikfi

mulher também 2sUJ-PAS-DIR-voltar

'E a mulher (disse): você chegou?'

(13) ata kinu na=bo fi-ticik-tja kinu

ele também lá=ALAT 3PL.POSS= parente-NF.PL também

$\varnothing-m \dot{t}-$ romo-ko=naha

3SUJ-NPAS-chegar-CONT-PL=PL.SUJ

'E ele (disse): os parentes dele também estão chegando para lá.'

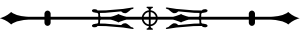


A discussão que segue sobre as duas partículas interrogativas ${ }^{7}$ está baseada em Silva (2011).

- Interrogativo 'fkaraba': esta partícula interroga sobre as condições de realização de um evento:

(14) amõ Jkaraba t ti-mi-ø

COMO INTER 2SUJ-NPAS-AUX

'Como você vai fazer?'

E também sobre as causas da existência de um referente:

(15) ito Kkaraba (Silva, 2011, p. 219)

fogo INTER

'Por que tem fogo?'

Skaraba pode constituir uma oração indepentende, como em (16), onde nittahiba é um marcador discursivo externo à oração constituída pela partícula:

$\begin{array}{lllll}\text { (16) ata duba are. } & \text { nittahiba } & \text { ग: Jkaraba } \\ \text { ele RESTR } & \text { ficar.em.casa } & \text { então } & \text { oh! } & \text { INTER }\end{array}$

'Ele ficou sozinho. Então (ele pensava): oh! Como? (é que ele faz para matar queixada)?'

- Interrogativo 'fa': Ja interroga sobre as condições de existência de um referente - sentença 1 - e, semelhante a אkaraba, interroga sobre as condições de realização de um evento - sentença 2:

(17) ta kta

este FOC.NF.SG INTER

'E este?

$\begin{array}{lll}h a=w a=t a & \text { la, } & \text { mĩjktJa } \\ \text { INTER }=\text { cOmo=NF.SG } & \text { INTER } & \text { genro }\end{array}$

Como este faz, genro?'

Sa interroga também sobre a localização de um referente:

(18) ito 迆 (Silva, 2011, p. 220)

fogo INTER

'Onde tem fogo?'

7 Além destas partículas, há outras formas interrogativas, o clítico ja e as proformas interrogativas, como visto em (3), (17) e (19); estas formas não serão discutidas aqui por não se tratar de partículas.

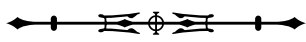


(19)

$\begin{array}{lll}h a ̃=n a=b o & \text { la } & u f=t a \\ \text { INTER=NF.DENS = ALAT } & \text { INTER } & \text { outro=NF.SG } \\ \text { 'Para onde foi o outro?' } & \end{array}$

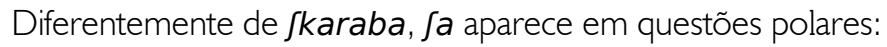

(20)
ikia La t $\int i-k$-a-difaha $=b a$
(Silva, 2011, p. 220)
você INTER 2SUJ-PAS-2SG.OBJ-alimentar-se $=$ COMPL
'Você se alimentou?'

- Negação 'bato': esta partícula nega predicados verbais (21) e não verbais (22):

(21)
ikra bato ka-naha-tja
$\varnothing-m i-\int i-w O \sim$ wo
eulF NEG 1sG.POSS-colares-NF.PL 1SUJ-NPAS-3PL.OBJ-RED furar

'Eu não vou furar meus colares.'

(22)
ikia katja bato a-paik
você FOC.F NEG 2sG.POSs-força
'Você é que não tem força.'

bato pode constituir uma oração independente quando empregada como resposta em uma questão polar (23), ou em uma questão de pedido de precisão (24), por exemplo:

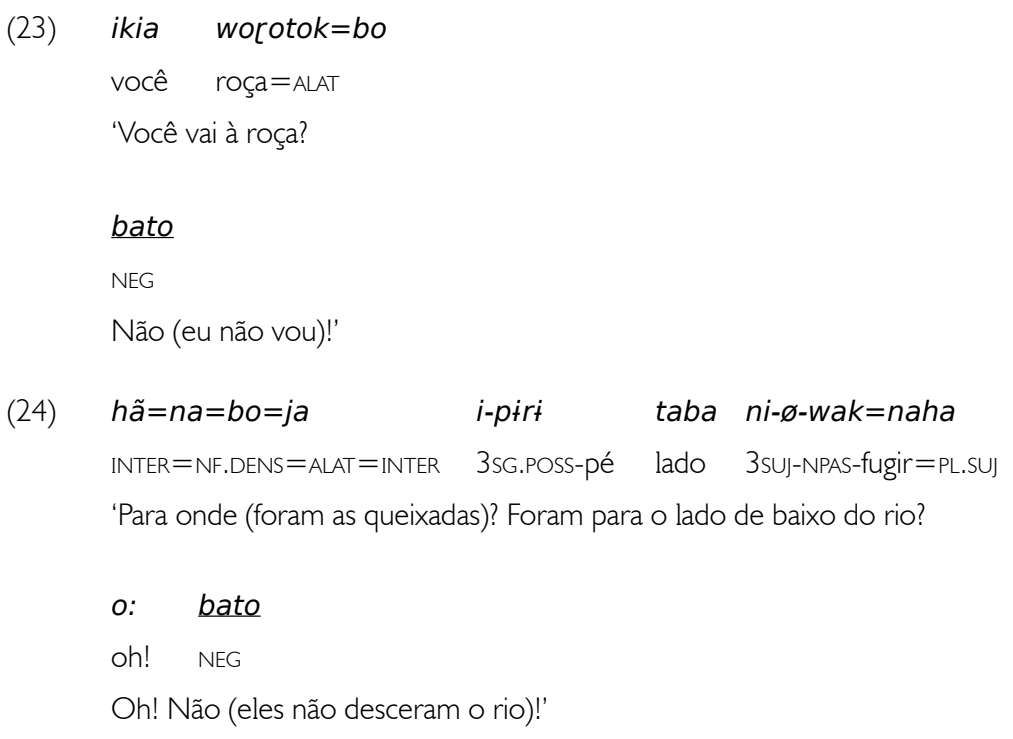

Em resposta a uma pergunta polar, bato aparece frequentemente associado à partícula de certeza enfática ba: 
(25) ta a-barikta

este 2sG.poss-marido

'- Este é seu marido?

bato $\underline{b a !}$

NEG C.ENF

-Não mesmo!'

- Incompletivo 'fiba': indica que o evento expresso pelo verbo não foi concluído. Esta partícula aparece com pouca frequência nos textos.

(26)

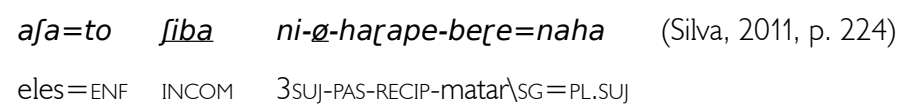

'Eles mesmos quase se mataram.'

(27)
parini $i$-t $\int a r i r i=t a$
Siba
$n i-\varnothing-\int i-b \partial r \partial$
onça 3sG-ser.vermelho $=$ NF.SG
INCOM
3SUJ-PAS-3PL.OBJ-comer

(Silva, 2011, p. 224)

'A onça vermelha quase os comeu.'

Em (27), parini itfaririta é um sintagma nominal constituído de nome e modificador, ocupando a primeira posição na sentença, seguido da partícula de segunda posição, fiba.

- Modalização de empatia ' $k t a, k t f a$ e ki': muito produtivas em narrativas míticas e no discurso cotidiano, este conjunto de partículas (Quadro 3) é empregado pelos falantes como uma estratégia para atenuar o discurso - no contexto de sentenças declarativas -, ou, ainda, atenuar uma ordem dada, deixando o discurso menos impositivo - nos contextos de sentenças exortativas e imperativas. Em ambos os casos, o falante deseja ganhar a simpatia do ouvinte.

Quadro 3. Partículas modalizadoras de empatia.

\begin{tabular}{|c|c|c|}
\hline Partícula & Locutor & Ouvinte \\
\hline $\mathrm{kta}$ & $\mathrm{NF}$ & $\mathrm{NF} . \mathrm{SG}$ \\
\hline $\mathrm{kt} J \mathrm{a}$ & $\mathrm{NF}$ & $\mathrm{NF} . \mathrm{PL} / \mathrm{F}$ \\
\hline $\mathrm{ki}$ & $\mathrm{F}$ & $\mathrm{NF} / \mathrm{F}$ \\
\hline
\end{tabular}

Estas partículas são parcialmente semelhantes às partículas focalizadoras. Como estas, $k$ ta e $k$ tja são morfologicamente complexas: são constituídas da forma $k$, seguida das marcas de gênero e número. Mas, diferentemente das focalizadoras, para referentes femininos, estas partículas têm a forma $k \dot{t}$ no lugar de katfa. Além disso, elas consideram o gênero e o número do ouvinte e do locutor e aparecem no final da sentença, seu escopo, enquanto as partículas focalizadoras consideram gênero e número apenas do referente focalizado e são de segunda posição, tendo

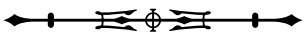


como escopo o sintagma imediatamente à sua esquerda. As partículas de empatia aparecem sempre em contexto explicitamente interativo, envolvendo locutor e ouvinte(s).

Seguem os contextos discursivos onde ocorrem, sendo que em todas elas são opcionais:

(i) Partículas de empatia em sentenças declarativas

O falante faz uma declaração ao ouvinte e emprega estas partículas com o objetivo de ter a simpatia deste, ao mesmo tempo em que demanda um 'parecer' do mesmo quanto ao conteúdo do seu discurso ${ }^{8}$.

kta: locutor não feminino singular/ouvinte não feminino singular

$\begin{array}{llll}\text { ग: } & \varnothing \text {-mi-wak } & \text { kta } & n i-\varnothing-a \\ \text { oh } & \text { 1sUJ-NPAS-caçar } & \text { EMP.NF/NF.SG } & \text { 3sUJ-PAS-AUX }\end{array}$

'Oh! eu vou caçar, disse ele.'

(Homem falando com outro homem)

Estruturas como em (28) são muito produtivas na língua; trata-se de duas sentenças que estão em uma relação de subordinação, a primeira sentença, $\varnothing$ - $m \dot{i}$-wak $k$ ta, sendo a dependente, e a sentença principal instituída pelo verbo auxiliar, como ilustrado abaixo. As partículas modalizadoras de empatia aparecem no final da sentença dependente:

\section{$\left[\left[\begin{array}{lll}0: & \varnothing-m i-w a k & k t a\end{array}\right]\right.$ ni-ø-a]]}

kt]a: locutor não feminino singular/ouvinte não feminino plural (29) e feminino singular (30):

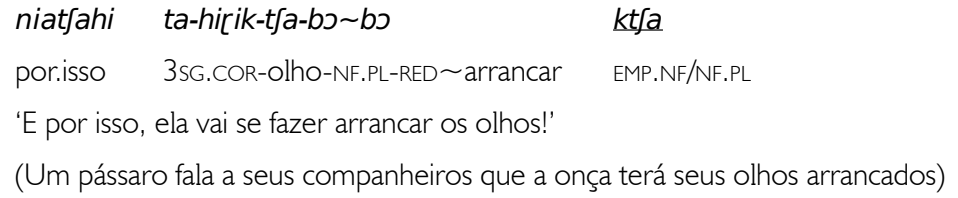

\begin{tabular}{|c|c|c|c|}
\hline$\varnothing-m \dot{t}-$ romo-ko & $d a$ & kt]a, & ka-rawə \\
\hline 1SUJ-NPAS-chegar-CONT & CERT & EMP.NF/F.SG & 1sG.POSS-irmã \\
\hline
\end{tabular}

$\underline{k i}$ : locutor feminino/ouvinte feminino (31) e não feminino singular (32) e plural (33):

8 Os Rikbaktsa não constumam tomar decisões individualmente, antes, compartilham com o outro o que pretendem fazer, como que esperando deste conselho ou aprovação. Também não parecem se sentir completamente à vontade para dar ordens ou solicitar algo ao interlocutor sem um atenuativo, daí o uso muito recorrente destas partículas, tanto no contexto de modalização de empatia quanto exortativo e imperativo.

9 Como veremos na seção "Gramaticalização de verbo auxiliar como reportativo", nas estruturas como em (28), o auxiliar parece estar se gramaticalizando como reportativo, e é traduzido por 'disse ela/ele'.

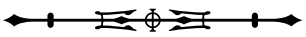


(31) ata kta ikra ka-barikta kí

ele FOC.NF.SG eulf 1sG.POSS-marido EMP.F/F

'É ele que será meu marido!'

(Uma mulher se dirigindo a outras mulheres)

(32)

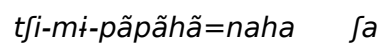

2sUJ-NPAS-espalhar $=P L . S U J \quad$ INTER

'- Vocês vão se espalhar?

\begin{tabular}{|c|c|c|}
\hline tfi-mi-pãpãrãhã=naha & $\underline{k \dot{t}}$ & \\
\hline 2sUJ-NPAS-espalhar =PL.SUJ & EMP.F/NF.SG & $\operatorname{sir}$ \\
\hline - Nós vamos nos espalhar & & \\
\hline
\end{tabular}

Em (33), o falante emprega a partícula de empatia com uma finalidade fática, para manter o contato com o ouvinte ativo, o que não deixa de ser uma demanda de simpatia por parte do locutor ao seu interlocutor:

$\begin{array}{lccl}\text { t } \int i-m \dot{i}-\text { romo-ko=naha } \quad d a \quad \underline{k \dot{i}} & k \dot{t} \int \mathrm{J} \\ \text { 2sUJ-NPAS-chegar-CONT=PL.SUJ } \quad \text { CERT } \quad \text { EMP.F/NF.PL } & \text { pessoal } \\ \text { 'Vocês estão mesmo chegando, pessoal?' } & \\ \text { (Uma mulher falando com os homens) } & \end{array}$

(ii) Partículas de empatia em sentenças exortativas

Diferentemente do imperativo, que é marcado por clíticos exclusivos, o modo exortativo não tem uma marca específica; é identificado pela prosódia, pelo verbo na primeira pessoa do plural e pela presença das partículas de empatia, que são opcionais. Elas são empregadas neste contexto para atenuar a exortação.

$\begin{array}{lll}\text { tfi-na-mõ } \tilde{o}=\text { naha } & \underline{k \dot{t}} & n i-\varnothing-\varnothing-k a r a \\ \text { 2sUJ-DIR-tomar.banho=PL.SUJ } & \text { EMP.F/F } & \text { 3sUJ-PAS-AUX-CONT }\end{array}$

'Vamos tomar banho, dizia ela.'

(Uma mulher se dirigindo a seus filhos)
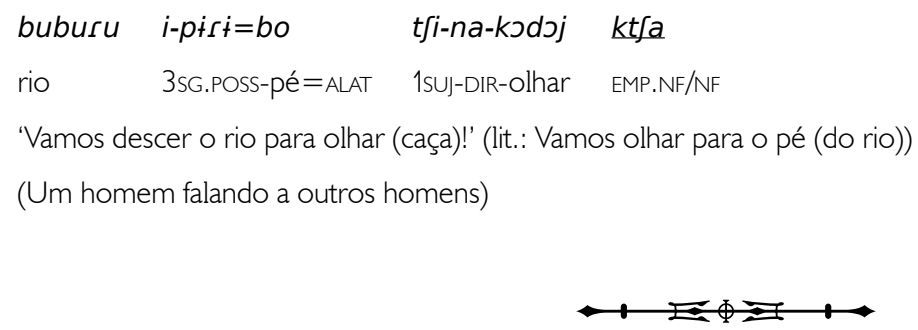
(iii) Partículas de empatia em sentenças imperativas ${ }^{10}$

O imperativo é marcado pelos clíticos ti/taha 'imperativo singular/plural'11. Neste contexto, semelhante ao que acontece com sentenças exortativas, as partículas modalizadoras de empatia têm a função de atenuar a ordem dada.

\begin{tabular}{|c|c|c|}
\hline$k a-b o$ & $t i=r-i k \int i=[\supset=n a h a$ & kt/a \\
\hline 1SG.POSS-ALAT & IMP.SG $=$ DIR-partir $=I T E R=P L . S U]$ & EMP.NF/F.PL \\
\hline
\end{tabular}

\begin{tabular}{|c|c|c|c|}
\hline ka: & $n i-\varnothing-\varnothing-k a r a$ & $\int \mathcal{S} \mathrm{J} k=t \dot{ }$ & \\
\hline grito.da.onça & 3SUJ-PAS-AUX-CONT & soltar $=I M P$ & EMP.NF/NF \\
\hline
\end{tabular}

Devido às semelhanças entre partículas focalizadoras e modalizadoras de empatia, seguem mais dados mostrando ambas ocorrendo em uma mesma sentença, para ilustrar os contextos de ocorrência de cada uma delas. Em (38) parte do exemplo (1) -, a partícula focalizadora $k$ ta focaliza o sujeito ta 'este', enquanto a partícula modalizadora $k t / a$ indica que se trata do genro falando com a sogra:

$\begin{array}{llll}\text { ta } \quad \underline{k t a} \quad i-t \int a p o-k o=t a & k t J a \\ \text { este } & \text { FOC.NF.SG } & \text { 3sG-dente-CONT=NF.SG } & \text { EMP.NF/F } \\ \text { 'É este que é um que tem dente.' } & \end{array}$

Abaixo, $k$ ta focaliza o sujeito ata 'ele', e $k \dot{t}$ indica que se trata de uma mulher falando com outras mulheres:
ata kta
ikita ka-bar ikta $\quad \underline{k i}$
(Silva, 2011, p. 218)
este FOC.NF.SG eulF 1SG.POSS-marido EMP.NF/F
'Oh! É este que será meu marido.'

Por fim, ainda sobre estas partículas, como mostram os dados em (28) e (37), kta é empregado quando o locutor não feminino singular se dirige a um ouvinte também não feminino singular. Porém, como mostrado em (40), está havendo uma extensão do emprego desta partícula, que passa a indicar também ouvinte não feminino plural,

10 Estas partículas podem ainda ser usadas em um contexto discursivo onde o falante faz uma advertência ao ouvinte:

\section{niatahi $\varnothing-p$-a-boro=hik $\quad \underline{k t a}$}

por.isso 1sUJ-NPAS-2OB.SG-COmer=PONT EMP.NF/NF.SG

'Por isso (ele disse): eu vou comer você!'

(Onça falando a um homem)

11 Os clíticos marcadores de imperativo ocorrem proclíticos ao verbo lexical quando o predicado é sintético, ou seja, instituído por um verbo principal na forma finita, como em (36); e ocorrem enclíticos a este mesmo verbo quando o predicado é complexo, isto é, o verbo lexical está na forma não finita, como em (37), o auxiliar estando ou não presente.

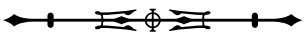


assumindo, assim, a função de $k t \int a$, que é usado pelo locutor não feminino singular quando este fala com um ouvinte não feminino plural e feminino (singular e plural). Se esta tendência se confirmar, haverá uma simplificação do Quadro 4, e kta passará a marcar locutor não feminino se dirigindo a ouvinte não feminino (singular e plural), enquanto $k t$ a se especializaria em contextos com locutor não feminino se dirigindo a ouvinte feminino (singular e plural):

Quadro 4. Partículas modalizadoras de empatia atualizadas.

\begin{tabular}{|c|c|c|}
\hline Partícula & Locutor & Ouvinte \\
\hline $\mathrm{kta}$ & $\mathrm{NF}$ & $\mathrm{NF}$ \\
\hline $\mathrm{kt} \int \mathrm{Na}$ & $\mathrm{NF}$ & $\mathrm{F}$ \\
\hline $\mathrm{ki}$ & $\mathrm{F}$ & $\mathrm{NF} / \mathrm{F}$ \\
\hline
\end{tabular}

Em (40), um homem fala a outros homens que sairão com ele para o mato; embora o ouvinte seja não feminino plural, o locutor usa a forma $k$ ta, e não $k t \jmath a$, para se dirigir a eles:

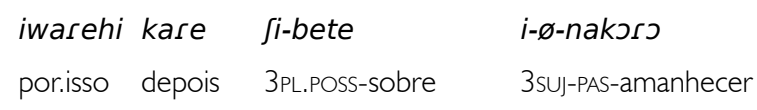

- Imperativo honorífico 'tekiahi e kikiahi'12: trata-se aqui da polidez gramaticalizada. A ordem expressa no imperativo é atenuada por estas partículas, empregadas como demonstração de respeito do falante para com o seu interlocutor. Elas são optativas, têm a setença como escopo, podem coocorrer com os clíticos imperativos e concordam com o gênero do locutor: tekiahi 'não feminino' e kikiahi 'feminino'ıె.

(41)

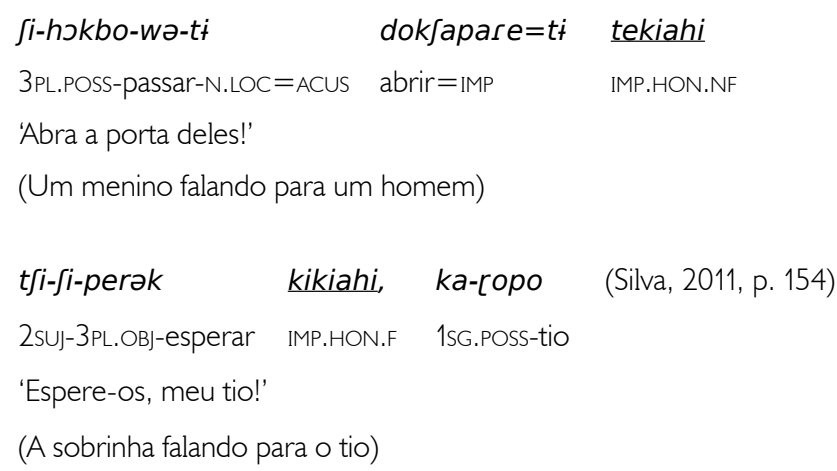

12 Silva (2011, p. 229) chama estas partículas de 'reforço do imperativo'.

13 Estas partículas parecem ser morfologicamente complexas, resultado da combinação das formas te e ki, respectivamente, seguidas da forma kiahi. Sincronicamente, ainda não está claro o significado de te e ki, e ambas as partículas parecem totalmente gramaticalizadas.

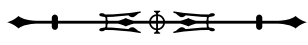


Há duas partículas de modalidade epistêmica que indicam certeza, $b a^{14}$ e da. Chamamos a primeira de 'certeza enfática' e a segunda, de 'certeza'. ba aparece em contexto explicitamente interativo, ou seja, em contexto de diálogo, enquanto da não necessariamente. A diferença entre as duas fica, portanto, evidente quando ambas estão em contexto explicitamente interativo, como em (43), que traz parte do diálogo entre genro e sogra. $\bigcirc$ falante usa ba para garantir que o conteúdo do seu discurso é altamente confível, não dando margem para ser contestado pelo ouvinte, que, por sua vez, usa da para garantir que o conteúdo do seu discurso é confiável, mas sem a ênfase expressa por ba.

- Certeza enfática 'ba':
ata kta
$\underline{b a}$
bato $[i-k-m i-b \supset r \supset$
ni-ø-ø-kara
ele FOC.NF.SG C.ENF NEG 3sUJ.HAB-PAS-1OB.PL-morder 3sUJ-AUX-PAS-CONT

(Silva, 2011, p. 134)

'Este mesmo não constuma morder a gente, dizia ele.

oh! iwa da
oh! assim CERT

Oh! Assim mesmo.'

No diálogo acima, usando ba, o genro expressa para a sogra sua certeza absoluta de que o bicho que está fazendo barulho não lhes morderá. Ela, por sua vez, responde usando da, expressando certeza do contrário, e que é preciso ficar atento ao bicho.

Além de sintagmas funcionando como argumento, como em (43), ba pode ainda ter como escopo circunstanciais (44) e uma sentença (45):

$$
\begin{array}{llllll}
n a=e r e & \underline{b a} & n a=w a & \underline{b a} & n i-\varnothing-\varnothing-k a=n a h a & n i-\varnothing-a \\
\text { aqui=LOC } & \text { C.ENF } & \text { isto=como } & \text { C.ENF } & \text { 3sUJ-AUX-PAS-CONT=PL.SUJ } & \text { 3SUJ-PAS-AUX }
\end{array}
$$

'É aqui mesmo; é assim mesmo que elas fazem, dizia ele (a si mesmo).'

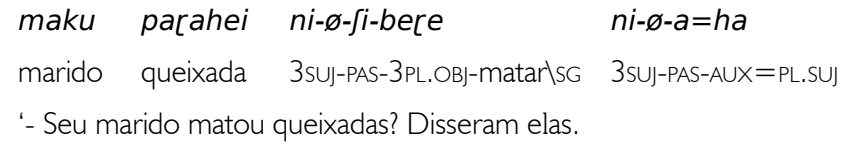

\footnotetext{
14 Boswood (1974) glosa a partícula ba como 'ênfase', e Silva (2011) chama de 'afirmativo'. É provável que ba tenha origem na palavra baba 'verdadeiro':

ka-naro baba Maha (Silva, 2011, p. 288)

1sG.POss-nome verdadeiro ANTROP.F

'Meu nome verdadeiro é Maha.'
}

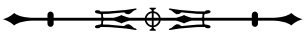


ni-ø-fi-bere $\quad$ ba

3SUJ-PAS-3OBJ.PL-matarlSG C.ENF

- Ele os matou mesmo!'

(Mulher responde às outras, querendo deixar claro que seu marido havia sido o primeiro rikbaktsa a matar queixada)

É muito produtiva a ocorrência de ba associada a outras partículas, como kta 'foco' (43) e (46) e kta 'empatia' (47):

(46) J: $m \dot{t}-t \int \dot{t} \quad \underline{k t a} \quad \underline{b a} \quad m \dot{t}-t u k=t o$

oh! 1POSS.PL-irmão FOC.NF.SG C.ENF 1POSS.PL-COM=ENF

'Oh! O nosso irmão mesmo está conosco!'

Associada às partículas de foco, ba aparecerá enclítica a esta, que tem a primazia da segunda posição.

A combinação ba + modalização de empatia, muito produtiva, resulta em uma locução que denota admiração (47-48). ba vem proclítica à partícula de empatia.

(47)

$\begin{array}{lllll}\text { nittahi } & \underline{\text { ba }} & \underline{\text { kta }} & \text { raro } & \text { [- } \varnothing \text {-epək } \\ \text { então } & \text { C.ENF } & \text { EMP.NF.SG/NF.SG } & \text { pirão } & \text { 3sUJ-PAS-acabar }\end{array}$

'Então, nossa! O pirão acabou!'

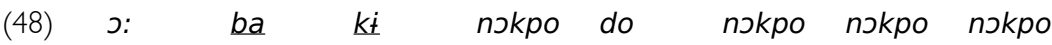

oh! C.ENF EMP.F andar subir andar andar andar

'Nossa! (elas se diziam) Elas andaram, subiram, andaram, andaram, andaram [...]'

- Certeza 'da': esta partícula aparecerá à direita do seu escopo, que pode ser qualquer tipo de constituinte, um sintagma nominal na função de sujeito (49), um circunstancial (50) e uma sentença (51).

(49) tõhi tihi o: ta da ø-p-i-bere

aquele ? oh este CERT 1SUJ-NPAS-3SG.OBJ-matarlSG

'Aquele (disse): oh! Certamente este vou matar (macaco).'

(50) tapara da ka-tripa tri-ri-bo kta

primeiro CERT 1sG.POSS-braço 2sUJ-DIR-arrancar EMP.NF/NF.SG

(Silva, 2011, p. 208)

'Certamente primeiro arranque meu braço!'

(Um homem instruindo falsamente uma onça sobre como fazer para comê-lo)

(51) i-ti həekik ni-ø-a $\underline{\text { da }}$

3sG-ACUS deixar 3sUJ-NPAS-AUX CERT

'Certamente ele a deixou (no mato).'

(Afirma a mulher depois que escureceu e sua mãe não voltou do mato)

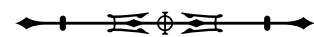


- Inferencial 'ke': esta partícula evidencial indica que a fonte da informação é o próprio falante, e que, em seu discurso, ele infere uma conclusão a partir de uma experiência pessoal ou leitura de mundo. ke aparecerá à direita do seu escopo, que pode ser um sintagma (52) ou uma sentença (53):

(52)

$\begin{array}{lllll}\text { J: } & \text { tohi } & \text { ke } & r-\varnothing-i k-b i k \dot{ } & t f i-m \dot{i}-\varnothing \\ \text { oh } & \text { este } & \text { INFER } & \text { 3sUJ-PAS-1SG.OBJ-terffilho } & \text { 2sUJ-NPAS-AUX }\end{array}$

'Oh! Parece que foi este quem me engravidou.'

(Sogra falando quando vê o genro, de quem ela havia marcado o rosto com genipapo na noite anterior, quando ele foi deitar-se com ela em sua rede)

(53)

$\begin{array}{llll}\text { J: } & \text { mi-difaha-wə } & \text { rio } & \underline{k e} \\ \text { oh } & \text { 1PL.POSS-comer-N.PAC } & \text { ser.bom } & \text { INFER }\end{array}$

'Oh! Parece que tem alimento bom!'

(Um homem falando quando vê, pela primeira vez, uma roça plantada)

- Restritivo 'duba': esta partícula tem como função restringir a leitura ao referente do constituinte ou ao evento sobre o qual ela tem escopo; ela aparece imediatamente à direita do mesmo, que pode ser qualquer tipo de sintagma - nominal (54) e verbal (55), por exemplo - ou uma sentença (56):

$\begin{array}{lllll}\text { ka-barikta } & \text { parahei-tJa } & \text { ripərək-tJa } & \underline{\text { duba }} & i-\varnothing-\int i-b a \\ \text { 1SG.POSS-marido } & \text { queixada-NF.PL } & \text { pequeno-NF.PL } & \text { RESTR } & \text { 3sUJ-PAS-3PL.OB-matarlPL }\end{array}$

'Meu marido matou somente queixadas pequenas.'

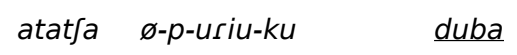

'Ela só chorava.' (chorava muito)

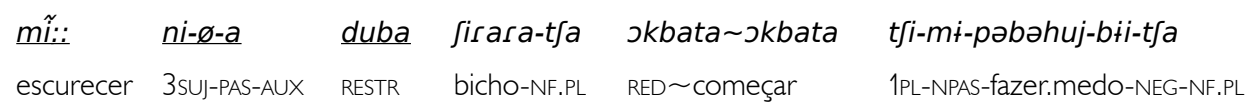

'Foi só escurecer, e os bichos começaram a fazer medo neles.'

Além da partícula de inferência ke, apresentada acima, o Rikbaktsa tem mais dois evidenciais: t faJowə 'reportativo' e o verbo auxiliar, que pode funcionar também como reportativo.

- Reportativo 'tfaJowə': esta partícula indica que o falante não é testemunha direta da informação que ele transmite, e não consegue recuperar a fonte da mesma. Ela aparece posposta à sentença, é pouco produtiva, e ocorre exclusivamente em narrativas míticas ${ }^{15}$.

\footnotetext{
15 É muito provável que tfaJowə tenha sua origem no verbo So 'narrar, contar', nominalizado pelo sufixo nominalizador de paciente -wə.
}

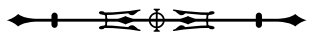




$\begin{array}{llllll}\text { niwatahi } & \text { ba } & \text { tapara=kta } & \text { boroi } & \text { ni-ø-ərik } & \text { tfafowə } \\ \text { por.isso } & \text { C.ENF } & \text { antigamente=NF.SG } & \text { lua } & 3 \text { SUJ-PAs-tornar.se } & \text { REP }\end{array}$

'E por isso mesmo, um (homem) de antigamente virou lua, eles dizem.'

$\begin{array}{llllll}\text { tapara } & \text { baba-ka } & \text { hui } & \text { oke }=r e & {[-\varnothing-\text { - } r u} & \text { tJafowa } \\ \text { primeiramente } & \text { verdadeiro-CONT } & \text { árvore } & \text { buraco=INES } & \text { 3sU]-PAS-dormir } & \text { REP }\end{array}$

'Verdadeiramente, primeiro ele dormiu no buraco de uma árvore, eles dizem.'

\section{GRAMATICALIZAÇÃO DE VERBO AUXILIAR COMO REPORTATIVO}

Aikhenvald (2004) propõe que a gramaticalização de verbos seja uma das origens dos evidenciais. Em Rikbaktsa, o verbo auxiliar a, traduzido por 'dizer/fazer', na terceira pessoa, passado, parece estar se gramaticalizando como reportativo. Ele ocorre no final da sentença e é traduzido pelos falantes como 'dizque', forma muito produtiva na variedade do português falado por este povo ${ }^{16}$.

Na função de auxiliar, este verbo aparece em construções perifrásticas, que se caracterizam pela presença de dois verbos, um lexical na forma não finita, e o auxiliar, que carrega as marcas de finitude (pessoa, tempo, direção e aspecto) (Silva, 2011).

Em (59), o verbo lexical arẽ 'ficar' está na forma não finita, enquanto o auxiliar porta o índice pessoal ni '3suj', correferente com o sujeito Wãba, e a marca de tempo ø- 'passado':

$\begin{array}{llll}\text { Wãba } & \text { duba } & \text { arê } & \text { ni- } \varnothing-a \\ \text { Wãba RESTR ficar } & 3 \text { sUJ-PAS-AUX }\end{array}$

'Somente Wãba ficou.'

O mesmo se passa em (60), onde o verbo lexical não finito é haî 'amarrar', e o auxiliar recebe as marcas de pessoa, tempo e aspecto:

$$
\begin{array}{llll}
\text { iktfa } & \text { rako } & \text { haî } & \text { ni- } \varnothing-\varnothing-k a r a^{17} \\
\text { olhar } & \text { preguiça } & \text { amarrar } & \text { 3sUJ-PAS-AUX-CONT }
\end{array}
$$

'Olharam e a preguiça estava amarrada.'

Por outro lado, os dados a seguir, uma sentença com predicado não perifrástico (61) e outra com predicado não verbal (62), ilustram contextos em que o auxilar não deveria aparecer, mas ele está presente, e funcionando como reportativo.

O predicado não perifrástico, ou sintético, se caracteriza pela presença apenas do verbo lexical, que está na forma finita, recebendo as marcas de pessoa, tempo, direção e aspecto, como em (57) e (58). Em (61), o narrador fala sobre as mulheres que antigamente saíam para o mato com os genros. O predicado é não perifrástico - o verbo lexical

\footnotetext{
16 Muitas vezes o falante viu ou ouviu diretamente da fonte sobre o fato narrado, mas, mesmo assim, ao falar sobre o assunto, ele usa o reportativo. Pode ser uma estratégia discursiva para não se comprometer com o conteúdo do discurso e, sobretudo, não comprometer o outro sobre quem fala, deixando sempre dúvida sobre o acontecido (algo como: 'diz que aconteceu, mas eu não sei...').

17 No contexto /i/_/k/, a vogal [a], raiz do auxiliar, sofre assimilação total pela vogal que a precede (Silva, 2011, p. 95).
}

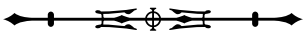


wak 'ir.para.o.mato' está na forma finita -, não haveria, portanto, necessidade da presença de um auxiliar, que tem aí uma leitura reportativa. Notemos ainda que, embora o sintagma nominal correferente com o sujeito (mulheres) não esteja presente, ele está subentendido, e o plural do sujeito (=naha) está marcado sobre o verbo lexical, enquanto a marca de sujeito que aparece sobre o auxiliar está no singular. $\bigcirc$ auxiliar não está, portanto, relacionado ao verbo lexical, mas a toda a sentença.

\begin{tabular}{|c|c|c|}
\hline tapara & taha-ste & $p i k-t \int a$ \\
\hline antigamente & 3PL.COR-filha & marido-NF.PL \\
\hline \multicolumn{2}{|c|}{ ri-k-na-wa-ka=naha } & $n i-\varnothing$ \\
\hline \multicolumn{2}{|c|}{ 3SUJ.HAB-PAS-DIR-andar-CONT } & UJ 3su \\
\hline
\end{tabular}

'dizque antigamente elas andavam com os maridos das filhas delas.'

Em (62), temos uma sentença existencial e, como tal, o núcleo do predicado é um nome. Mesmo em uma estrutura que não exige a presença de um verbo, o auxiliar está presente, claramente como reportativo, e não como locus das marcas de finitude.

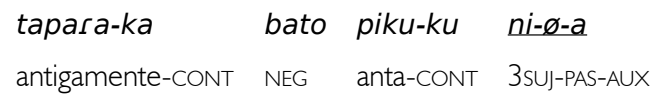

É interessante ainda dizer que o auxiliar também introduz citação direta, como nos exemplos (28) e (63). Nestes casos, ele é traduzido por 'disse ela/ele'. Em (63) - uma mulher falando com suas companheiras -, o verbo lexical әрәk 'fazer crescer' está na forma finita e no não passado, enquanto o auxiliar está no passado. Além disso, as duas formas verbais estão separadas por um sintagma nominal, katfe, o que não poderia ocorrer se eles estivessem no mesmo sintagma. Os dois verbos, portanto, não têm relação sintática.
$i k r a \quad \varnothing-m i-r-i-ə p \partial k$
$k a-t \int e$
ni-ø-a
eulF 1suJ-NPAS-DIR-3sG.OBJ-fazer.crescer
1sG.POss-filho
3SUJ-PAS-AUX
'Eu vou criar ele como meu filho, ela disse.' (lit.: Eu vou fazer ele crescer meu filho, ela disse)

Os diferentes usos do auxiliar vistos aqui nos ajudam a traçar esse processo de gramaticalização que parece ir de verbo auxiliar 'dizer/falar' a verbo de citação (quotativo) e evidencial (reportativo).

- Assertivo ' $h \ddot{t}$ ': a partícula $h \dot{t}$ indica que o locutor atesta, com ênfase, o conteúdo da proposição, e deseja convencer seu interlocutor do mesmo. Ela ocorre posposta à sentença.

A seguir, destaca-se trecho de um diálogo em que um homem conta à sua mulher que viu saúvas quando foi caçar:

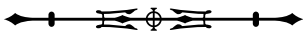


(64)

$\begin{array}{lll}\text { Simatfirik-tJa } & \text { [i-ø-po-bajk=naha } & \underline{h \dot{t}} \\ \text { saúva-NF.PL } & \text { 3sUJ-PAS-Sair-COMPL=PL.SUJ } & \text { ASS }\end{array}$

'As saúvas saíram todas.

$\begin{array}{llll}\text { aba-ka=re } & \text { unata } & \varnothing-m \dot{t}-\text { para=naha } & \underline{h \dot{t}} \\ \text { agora-CONT=SUB } & \text { à.noite } & \text { 3sUJ-NPAS-Voar=PL.SUJ } & \text { ASS }\end{array}$

Depois de agora, à noite, elas vão voar.'

Também evidencia-se trecho de uma narrativa em que uma mulher pede às suas companheiras que não temam a anta, um personagem mítico, pois ele é humano.

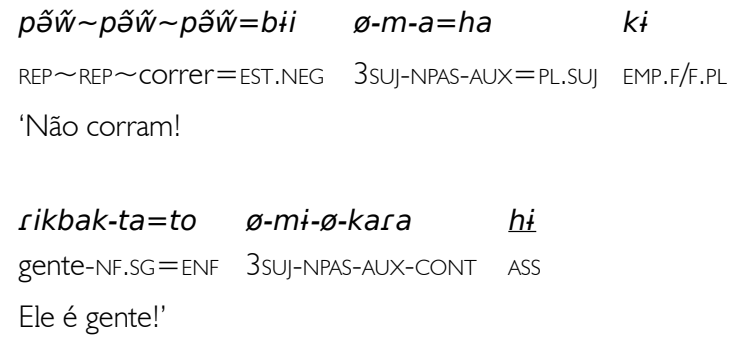

- Irrealis ' rika': esta partícula aparece em sentenças que se assemelham às do português do tipo 'se A, B', que em Rikbaktsa é 'A rika, B', com a partícula vindo imediatamente à direita da sentença subordinada (protasis), seu escopo, e funcionando como um operador condicional; a realização da setença principal está condicionada à realização do evento descrito na subordinada.

(66)

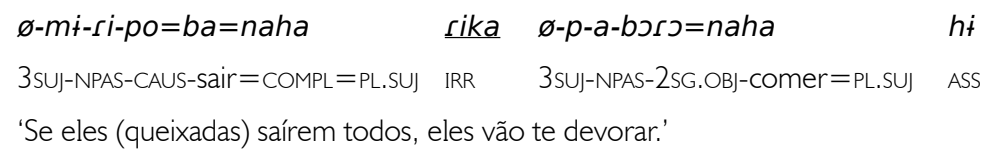

No trecho abaixo, a onça faz uma reflexão ao ouvir o barulho de um bicho, e condiciona devorá-lo a ele ser bom, apetitoso.
'O que será? Se for muito bom, eu vou comer, disse ele.' (lit.: se for muito bom, haverá o uso dos meus dentes)

Conservando a semântica de irrealis, rika pode ainda ocorrer em uma estrutura sem a presença de uma sentença condicionante/subordinada. A seguir, há um diálogo entre a onça e o tamanduá, no qual ele pergunta a ela como ela faria com ele se eles não fossem amigos.

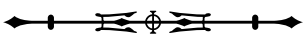


(68) ग: rika fa

oh! IRR INTER

'E como seria?

$\begin{array}{lll}h a=w a & \text { rika } & \text { ni-ø-a } \\ \text { INTER }=\text { cOMO } & \text { IRR } & \text { 3sUJ-PAS-AUX }\end{array}$

Como você faria? disse ele' [...]

Em seguida, após ter feito uma demonstração, caçando um bicho na frente do tamanduá, ela responde.

$\begin{array}{lllllllll}\text { (69) } & \text { J: } & \text { iwa } & \underline{\text { rika }} & \text { na=wa } & \text { rika } & \text { kta } & a-t \dot{ } & n i-\varnothing-a \\ & \text { oh! } & \text { assim } & \text { IRR } & \text { isto=como } & \text { IRR } & \text { EMP.NF/NF.SG } & \text { 2sG-ACUS } & \text { 3suJ-PAS-AUX }\end{array}$

'Seria assim, eu faria assim com você, disse ela.'

- Incredulidade 'ma': esta partícula evidencia a incredulidade do ouvinte em relação ao discurso do falante. A incredulidade pode ser forte, quando o ouvinte põe em questão o que diz o falante, quase que encerrando o assunto (70), ou fraca, quando o ouvinte até toma por verdade o discurso do falante, mas 'pede' mais evidências (71). Poderia ser traduzido em português pelas formas 'sei...', 'será?', ou 'ãhã...'

(70) tat $\int a=$ to ke tat $\int a=t u k$

aquela $=\mathrm{ENF} \quad \mathrm{CERT} \quad$ aquela $=\mathrm{COM}$

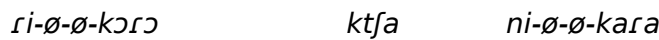

3SUJ-PAS-3SG.OBJ-queimar EMP.NF/F.SG 3SUJ-AUX-PAS-CONT

'(Ele dizia): certamente aquela e a companheira dela me queimaram.

i-je kinu ma

3sG.POSS-mãe também INCRED

E a mãe dele (disse): sei...'

(A anta contando à sua mãe o que lhe acontecera)

(71) i-k-si-piktomo

1SUJ-PAS-3PL.OBJ-encontrar

'Eu os encontrei (queixadas)

$\underline{m a}$

INCRED

Será?'

(Diálogo entre um homem e sua esposa)

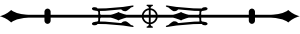




\section{PARTÍCULA FÁTICA}

- Sim 'nithi $\sim \boldsymbol{i} h \dot{i} \sim \boldsymbol{h i t '}$ ': em geral, aparecem à esquerda da sentença ou constituindo uma oração independente. Estas partículas são usadas em resposta a perguntas polares (72) ou como demonstração de concordância do ouvinte com o falante (73-74). Aparentemente, as três formas podem ocorrer nos mesmos contextos.

(72) witik kinu tji-k-r-ikJi

mulher também 2suJ-PAS-DIR-Voltar

'A mulher (disse): você chegou?

$$
\begin{array}{lll}
\underline{i h t} & i-k-r-i k f i & k t f a \\
\operatorname{sim} & \text { 1sUJ-PAS-DIR-Voltar } & \text { EMP.NF.SG/F }
\end{array}
$$

Sim, eu cheguei!'

$\begin{array}{llll}\text { (73) niatahiba } & \varnothing-p-i k f i=[\supset & n i-\varnothing-a & \text { nithi } \\ \text { então } & \text { 3sUJ-PAs-Voltar=ITER } & \text { 3sUJ-PAS-AUX } & \text { sim }\end{array}$

'Então (ele disse): - eu vou voltar novamente. - Sim (eles concordaram).'

(74) ka-boto ti-rebək=naha ktja

1SG.POSS-flecha IMP.SG-buscar-PL.SU] EMP.NF.SG/F

'- Busque minha flecha.

$\underline{h \ddot{+}}$

$\operatorname{sim}$

- Sim.

i-ti wabehək

3sG-ACUS pegar

Ela a pegou.'

\section{CONSIDERAÇÕES FINAIS}

As formas que chamamos de partículas aqui não poderiam ser agregadas à classe dos nomes por lhes faltar características destes, como referir e instituir predicado, por exemplo. Tampouco poderiam figurar entre os advérbios por, diferentemente destes, não admitirem ser nominalizados nem aceitarem o sufixo de intensidade que pode acompanhá-los. Não parece igualmente ser o caso de chamá-las de clíticos, pois existem características fonológicas e gramaticais que distinguem esses dois conjuntos (partículas e clíticos). Do ponto de vista fonológico, a ocorrência do acento. Partículas são acentuadas e os clíticos, não. Do ponto de vista gramatical, um aspecto importante emerge quando se compara partículas de foco e empatia e os clíticos nominalizadores. Apesar da semelhança de forma entre ambos os conjuntos, os clíticos participam de processos morfológicos e as partículas, não.

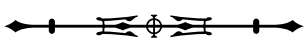


Com respeito ao fato de as partículas instituírem uma oração independente, embora sejam morfemas gramaticais, vimos que algumas delas podem, além das funções primárias que desempenham, instituir uma oração independente, como é o caso das partículas de negação bato e fática ‘h ' 'sim', ou ainda da sequência formada por ba kt $\int a$ (certeza enfática + modalização de empatia). Esta propriedade é restrita a algumas partículas e provavelmente se dê pelo fato de, como afirma Queixalós (2019, p. 732) - falando sobre as partículas do Sikuani, neste número -, "[...] devido à alta frequência na fala espontânea, tendem a ampliar o leque de suas funções semânticas ou pragmáticas".

Os dados do Rikbaktsa parecem, portanto, corroborar a existência de uma classe de partículas, com características formais próprias.

\section{AGRADECIMENTOS}

O presente artigo tem como base a tese intitulada "Morphosyntaxe du Rikbaktsa (Amazonie brésilienne)", apresentada para obtenção do título de Doutora em Linguistica Teórica, Descritiva e Automática pela Université Denis Diderot - Paris 7, França.

\section{ABREVIATURAS}

$\begin{array}{llllll}1 & \text { primeira pessoa } & \text { EMP } & \text { empatia } & \text { M } & \text { masculino } \\ 2 & \text { segunda pessoa } & \text { ENF } & \text { ênfase } & \text { NEG } & \text { negação } \\ 3 & \text { terceira pessoa } & \text { EST.AFIR } & \text { estativo afirmativo } & \text { NF } & \text { não feminino } \\ \text { ACUS } & \text { acusativo } & \text { EST.NEG } & \text { estativo negativo } & \text { N.LOC } & \text { nominalização de local } \\ \text { ALAT } & \text { alativo } & \text { F } & \text { feminino } & \text { N.PAC } & \text { nominalização de paciente } \\ \text { ANTROP } & \text { antropônimo } & \text { FOC } & \text { focalização } & \text { NPAS } & \text { não passado } \\ \text { ASS } & \text { assertivo } & \text { HAB } & \text { habitual } & \text { OBJ } & \text { objeto } \\ \text { AUX } & \text { auxiliar } & \text { HON } & \text { honorífico } & \text { PAS } & \text { passado } \\ \text { CAUS } & \text { causativo } & \text { IMP } & \text { imperativo } & \text { PL } & \text { plural } \\ \text { C.ENF } & \text { certeza enfática } & \text { INCOM } & \text { incompletivo } & \text { PONT } & \text { pontual } \\ \text { CERT } & \text { certeza } & \text { INCRED } & \text { incredulidade } & \text { POSS } & \text { possessivo } \\ \text { COM } & \text { companhia } & \text { INES } & \text { inessivo } & \text { RECIP } & \text { recíproco } \\ \text { COMPL } & \text { completivo } & \text { INFER } & \text { inferencial } & \text { RED } & \text { reduplicação } \\ \text { CONT } & \text { continuativo } & \text { INTENS } & \text { intensificador } & \text { REP } & \text { repetição } \\ \text { COR } & \text { correferencial } & \text { INTER } & \text { interrogativo } & \text { RESTR } & \text { restritivo } \\ \text { DENS } & \text { denso } & \text { IRR } & \text { irrealis } & \text { SG } & \text { singular } \\ \text { DIF } & \text { difuso } & \text { ITER } & \text { iterativo } & \text { SUB } & \text { subordinador } \\ \text { DIR } & \text { direção } & \text { LOC } & \text { locativo } & \text { SUJ } & \text { sujeito }\end{array}$

\section{REFERÊNCIAS}

AIKHENVALD, Alexandra Y. Evidentiality. Oxford: Oxford University Press, 2004.

BOSWOOD, Joan. Citações no discurso narrativo da língua Rikbaktsa. In: BOSWOOD, Joan. Linguistics. Brasília: Summer Institute of Linguistics, 1974. p. 99-129. (Série Linguística, n. 3).

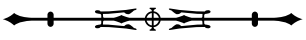


CARON, Bernard. Assertion et préconstruit: topicalization et focalisation dans les langues africaines. In: CARON, Bernard (ed.). Topicalisation et focalisation dans les langues africaines. Paris: Peeters, 2000. p. 8-42.

CRYSTAL, David. A dictionary of linguistics and phonetics. Oxford: Blackwell Publishing, 2008.

GIVÓN, Talmy. Syntax: a functional typology introduction. Amsterdam: John Benjamins Publishing Company, 2001. v. 1.

LEMARÉCHAL, Alain. Les parties du discours: sémantique et syntaxe. Paris: Presses Universitaires de France, 1989.

PAYNE, Thomas E. Exploring language structure: a student's guide. Cambridge: Cambridge University Press, 2006.

QUEIXALÓS, Francesc. Partículas em Sikuani. Boletim do Museu Paraense Emílio Goeldi. Ciências Humanas, Belém, v. 14, n. 3, p. 721-737, set./dez. 2019. DOI: http://dx.doi.org/10.1590/1981.81222019000300003.

SCHACHTER, Paul. Parts-of-speech systems. In: SHOPEN, Timothy (ed.). Language typology and syntactic description. Cambridge: Cambridge University Press, 1985. v. 1, p. 3-61.

SILVA, Léia de Jesus. Morphosyntaxe du Rikbaktsa (Amazonie brésilienne). 2011. Tese (Doutorado em Linguística) - Université Denis Didetot, Paris, 2011.

ZWICKY, Arnold M. Clitics and particles. Language, [S.I.], v. 61, n. 2, p. 283-305, June 1985.

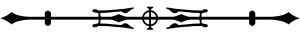

